\title{
Bacillus thuringiensis Berliner e Anticarsia gemmatalis Hübner (Lepidoptera: Erebidae) sob ação de extratos vegetais
}

\section{Bacillus thuringiensis Berliner and Anticarsia gemmatalis Hübner (Lepidoptera: Erebidae) under the action of plant extracts}

\author{
Alciani da Silva Pessoa', Everton Ricardi Lozano ${ }^{\text {* }}$, Andréia Vilani ${ }^{1}$, Michele Potrich ${ }^{1}$, \\ Lísia de Lima Matos ${ }^{1}$, Thiego Mateus Oliveira', Gustavo Marçal Pessoa'
}

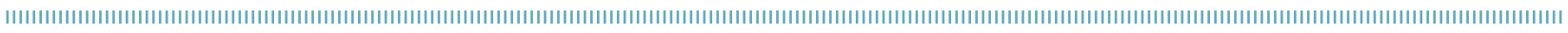

RESUMO: O objetivo deste trabalho foi avaliar o efeito de extratos vegetais aquosos de jamboláo, Syzygium cumini (L.) Skeels (Myrtaceae), mamona, Ricinus communis (L.) (Euphorbiaceae), uva-do-japão, Hovenia dulcis (Thumberg) (Rhamnaceae) e urucum (Bixa orellana (L.) (Bixaceae), na concentração de 10\%, sobre Bacillus thuringiensis subesp. kurstaki (Btk) e sobre Anticarsia gemmatalis (Lepidoptera: Erebidae) e a associação destes sobre $A$. gemmatalis, em condiçôes de laboratório. Os tratamentos constaram dos extratos aquosos e Btk isoladamente e a mistura de cada extrato com Btk. Estes foram incubados em agitador horizontal $\left(30 \pm 2^{\circ} \mathrm{C}, 150 \mathrm{rpm}\right.$ por $2 \mathrm{~h}$ ) e, em seguida, aplicados sobre cubos de dieta artificial para $A$. gemmatalis, em placas de Petri. Como testemunha utilizou-se água destilada esterilizada. Cada tratamento constou de 4 placas de Petri (repetição), com 25 lagartas de segundo ínstar cada. Estas foram acondicionadas em câmara climatizada (27 $\pm 2^{\circ} \mathrm{C}$, , umidade relativa $70 \pm 10 \%$ e fotofase $14 \mathrm{~h}$ ), avaliando-se a mortalidade após 24,48 e $72 \mathrm{~h}$. Também foram avaliados o percentual de empupamento e o peso das pupas dos insetos sobreviventes. Nenhum dos extratos apresentou efeito inseticida para $A$. gemmatalis e efeito negativo para os cristais de Btk. A mortalidade acumulada causada pelos extratos de uva-do-japão, jamboláo, urucum e mamona foram, respectivamente, de 54,73; 46,09; 47,19 e 65,73\%; diferindo significativamente da testemunha $(95,74 \%)$. O peso médio das pupas não diferiu significativamente entre os tratamentos. A associação dos extratos de uva-do-japão, colorau e mamona com Btk provocou mortalidade acumulada de $100 \%$ em $A$. gemmatalis.

PALAVRAS-CHAVE: extratos botânicos; controle alternativo; controle associado.

\begin{abstract}
This study aimed to evaluate the effect of aqueous plant extracts of jambolan, Syzygium cumini (L.) Skeels (Myrtaceae), castor bean, Ricinus communis (L.) (Euphorbiaceae), grape japan, Hovenia dulcis (Thumberg) (Rhamnaceae) and urucum, Bixa orellana (L.) (Bixaceae) at a concentration of $10 \%$ on Bacillus thuringiensis subsp kurstaki (Btk) and on Anticarsia gemmatalis (Lepidoptera: Erebidae), and the association of these on A. gemmatalis. The treatments consisted of aqueous extracts and Btk alone and the mixture of extract with Btk. These were incubated in a horizontal shaker $\left(30 \pm 2^{\circ} \mathrm{C}, 150 \mathrm{rpm}\right.$ for $\left.2 \mathrm{~h}\right)$ and then applied to artificial diet cubes for $A$. gemmatalis in Petri dishes. As a control it was used sterile distilled water. Each treatment consisted of 4 Petri dishes (repetition) with 25 second instar larvae each. The disches were placed in a climatic chamber $\left(27 \pm 2^{\circ} \mathrm{C}\right.$, relative humidity $70 \pm 10 \%$ and 14 h photoperiod), assessing the mortality after 24,48 and $72 \mathrm{~h}$. The percentage pupal and pupae weight of surviving insect were also assessed. None of the extracts showed insecticidal effects for $A$. gemmatalis and negative effects for crystals Btk. The cumulative mortality caused by extracts of grape japan, jambolan, urucum and castor bean were respectively $54.73 ; 46.09 ; 47.19$ and $65.73 \%$, differing significantly from the control (95.74\%). The average weight of pupae did not differ significantly among treatments. The association of extracts of grape japan, urucun and castor bean with Btk caused $100 \%$ cumulative mortality in A. gemmatalis.
\end{abstract}

KEYWORDS: botanical extracts; alternative control; associated control.

\footnotetext{
'Laboratório de Controle Biológico; Universidade Tecnológica Federal do Paraná (UTFPR) - Dois Vizinhos (PR), Brasil.

*Autor correspondente: evertonlricardi@utfpr.edu.br

Recebido em: $11 / 09 / 2012$. Aceito em: 03/10/2014.
} 


\section{INTRODUÇÃO}

A utilização excessiva de inseticidas químicos sintéticos causa consequências graves ao homem e ao ambiente, devido à alta toxidade e ao amplo espectro de ação (PrAÇA et al., 2004), além de causar a seleção de populaçóes de pragas resistentes, o surgimento de novas pragas, antes consideradas secundárias, e a morte dos organismos não alvo, como os polinizadores e os inimigos naturais (SCHLÜTER, 2006; BerlitZ; FIUZA, 2005).

Com isso é cada vez mais urgente e necessária a busca pela sustentabilidade agrícola por meio de práticas alternativas, orientadas pelo conhecimento de processos ecológicos em consonância ao contexto social (GLIESSMAN, 2005). Práticas alternativas servem de base aos sistemas alternativos de produção, contribuindo na redução dos impactos ambientais e sociais causados pelo modelo convencional de produção agrícola (Diniz et al., 2006).

Nos sistemas alternativos, o controle de pragas e doenças é realizado por meio da utilização de extratos vegetais, óleos essenciais, caldas fertiprotetoras, além do uso de agentes de controle biológico (Penteado, 2007).

Os agentes de controle biológico representam uma alternativa econômica e ecologicamente viável (PrAçA et al., 2004) e, entre os agentes de controle, destaca-se Bacillus thuringiensis Berliner, bactéria Gram positiva que produz proteínas inseticidas na forma de cristais parasporais durante a esporulação (Bravo et al., 2007), podendo cada isolado produzir um ou mais tipos de cristais, variando seu espectro inseticida (FIUZA, 2009).

B. thuringiensis subesp. kurstaki apresenta efeito inseticida a diversos insetos-praga como Spodoptera frugiperda J.E. Smith (Lepidoptera: Noctuidae), Anticarsia gemmatalis Hübner (Lepidoptera: Erebidae), Anthonomus grandis Boheman (Coleoptera: Curculionidae), Aedes aegypti Linnaeus, Culex quinquefasciatus Say (Diptera: Culicidae) (Praça et al., 2004) e Plutella xylostella Linnaeus (Lepidoptera: Plutellidae) (Medeiros et al. 2005a). Santos et al. (2009) consideraram a estirpe $B$. thuringiensis subesp. kurstaki (Btk) HD-1 altamente patogênica a Spodoptera eridania Cramer, Spodoptera cosmioides Walker $e$ S. frugiperda (Lepidoptera: Noctuidae).

A utilização de extratos vegetais também representa uma alternativa importante no controle de insetos-praga, visto que muitos apresentam potencial inseticida, baixa toxicidade ao homem, aos animais e ao ambiente. Esses extratos apresentam substâncias bioativas (Medeiros et al., 2005b), resultantes do metabolismo secundário das plantas. Essas substâncias podem apresentar efeito tóxico (Prates et al., 2003), ovicida, repelente (FranÇA et al., 2009), antialimentar (SAIto et al., 2004), além de agirem como reguladores de crescimento e inseticidas fisiológicos (MAIRESSE, 2005).

Os metabólitos secundários encontrados nos extratos vegetais podem apresentar atividade antibacteriana, como observado para o extrato hidroalcoólico de folhas de jamboláo, S. cumini (Loguercio et al., 2005; Michelin et al., 2005), para tinturas de urucun, B. orellana (СовLHo et al., 2003), para os extratos metanólicos e hexânicos de velame do campo, Croton campestris (A.), alfavaca, Ocimum gratissimum (L.), e erva baleeira, Cordia verbenacea DC (MATias et al. 2010).

Para a manutenção dos sistemas alternativos de produção, em muitas situações, faz-se necessária a associação de duas ou mais estratégias de controle, visando atingir diferentes espécies de insetos-praga e/ou diferentes fases do desenvolvimento. Desta forma, estudos de compatibilidade entre extratos vegetais e bactérias entomopatogênicas são importantes, pois mesmo os extratos sendo mais seguros do que os produtos fitossanitários sintéticos, podem agir sobre esses agentes alterando seu modo de açấo. Além disso, o efeito da associação dos extratos e bactérias entomopatogênicas pode melhorar a eficácia de controle, apresentando efeitos diretos ou subletais.

Nesse sentido, o objetivo deste trabalho foi avaliar o efeito de extratos vegetais aquosos sobre $B$. thuringiensis subesp. kurstaki e sobre $A$. gemmatalis e a associação destes sobre a A. gemmatalis, em condiçôes de laboratório.

\section{MATERIAL E MÉTODOS}

O experimento foi conduzido no Laboratório de Controle Biológico da Universidade Tecnológica Federal do Paraná, Campus Dois Vizinhos (UTFPR-DV).

Para a realização dos bioensaios, ovos de $A$. gemmatalis foram fornecidos pela Empresa BSBio - Produtos Biológicos de Cascavel, Paraná, em recipientes contendo dieta artificial para A. gemmatalis (Hoffmann-Campo et al., 1985). Os ovos foram mantidos em câmara climatizada à temperatura de $27 \pm 2^{\circ} \mathrm{C}$, umidade relativa (UR) de $70 \pm 10 \%$ e fotofase $14 \mathrm{~h}$ até as lagartas atingirem o segundo ínstar. A bactéria utilizada foi B. thuringiensis subesp. kurstaki (Btk), obtida do produto comercial Dipel $\mathrm{PM}^{\circledR}$.

\section{Obtenção dos extratos vegetais}

As plantas utilizadas foram jamboláo, Syzygium cumini (L.) Skeels (Myrtaceae), mamona, Ricinus communis (L.) (Euphorbiaceae), e uva-do-japão, Hovenia dulcis (Thunberg) (Rhamnaceae), obtidas em Dois Vizinhos, Paraná, e urucum, Bixa orellana L. (Bixaceae), obtida em Enéas Marques, Paraná. Folhas e ramos das plantas foram coletados no período matutino e transferidos para estufa de secagem $\left(60^{\circ} \mathrm{C}\right)$ por $48 \mathrm{~h}$. Uma exsicata de cada planta foi enviada ao Herbário da UTFPR-DV para a identificaçấo botânica e o registro do exemplar voucher. Posteriormente, as plantas secas foram moídas em moinho de facas do tipo Willye, TECNAL ${ }^{\circledR}$, modelo TE650, até granulometria de $0,45 \mathrm{~mm}$. O pó, obtido pela trituraçáo dos vegetais, foi armazenado em recipientes de vidro fechados, identificados e isolados da exposiçâao à luz até seu uso na elaboraçáo dos extratos. Para obtenção do extrato aquoso foi utilizada água 
destilada esterilizada como solvente extrator, sendo adicionados $25 \mathrm{~g}$ de pó em $250 \mathrm{~mL}$ de água, permanecendo $48 \mathrm{~h}$ ao abrigo da luz, em temperatura ambiente. Em seguida, a mistura foi filtrada com dupla camada de papel filtro esterilizado utilizando uma bomba a vácuo, marca $\mathrm{FABEN}^{\circledR}$, com pressão constante de $1,2 \mathrm{kgf} / \mathrm{cm}^{2}$ acoplada a um Kitasato. A solução final foi armazenada em frascos esterilizados, identificados, fechados e conservados em geladeira com temperatura de $4^{\circ} \mathrm{C}$, sendo denominada entáo "extrato aquoso a 10\%".

\section{Determinação da concentração de Bacillus thuringiensis subesp. kurstaki utilizada}

A partir do produto comercial Dipel $\mathrm{PM}^{\circledR}$, na concentração recomendada para o controle de $A$. gemmatalis (250 g/ha/ $100 \mathrm{~L} \mathrm{H}_{2} \mathrm{O}$ ), foram preparadas 6 suspensōes equivalentes às concentraçôes de 250, 225, 200, 175, 150 e $125 \mathrm{~g} / \mathrm{ha} / 100 \mathrm{~L} \mathrm{H}_{2} \mathrm{O}$, em um volume de $50 \mathrm{~mL}$, em frascos Erlenmeyer. Para tal, foram adicionadas, respectivamente, 0,$125 ; 0,113 ; 0,100 ; 0,088 ; 0,075 \mathrm{e}$ $0,063 \mathrm{~g}$ do produto comercial em $50 \mathrm{~mL}$ de água destilada esterilizada. Foi preparada a dieta artificial para $A$. gemmatalis, livre de anticontaminante, e após a solidificação foram cortados cubos de aproximadamente $1,5 \mathrm{~cm}$ de lado. Para cada tratamento foram preparadas quatro placas de Petri (repetiçôes), com três cubos de dieta cada. Em cada cubo foram adicionados $150 \mu \mathrm{L}$ das suspensões, com auxílio de um micropipetador automático. A testemunha constou da aplicaçâo de água destilada esterilizada. Após a aplicação dos tratamentos, as placas ficaram abertas em câmara de fluxo laminar, por cinco minutos, para a evaporaçáo do excesso de água, e receberam 25 lagartas de segundo ínstar de $A$. gemmatalis cada. Posteriormente, as placas foram fechadas e acondicionadas em câmara climatizada à temperatura de $27 \pm 2^{\circ} \mathrm{C}$, UR $70 \pm 10 \%$ e fotofase $14 \mathrm{~h}$. As avaliaçóes foram realizadas após 24,48 e $72 \mathrm{~h}$, quantificando o número de lagartas mortas. A confirmaçáo da mortalidade das lagartas foi feita observando os sinais e sintomas, conforme Habib; AndRade (1998).

Foi selecionada a metade da concentraçáo recomendada de $125 \mathrm{~g}$ do produto comercial/ha/ $100 \mathrm{~L} \mathrm{H}_{2} \mathrm{O}(=0,063 \mathrm{~g} / 50 \mathrm{~mL})$, que causou $80 \%$ de mortalidade em $A$. gemmatalis, possibilitando assim a avaliação sobre o modo de ação do patógeno.

\section{Efeito dos extratos vegetais sobre Anticarsia gemmatalis e sobre cristais de Bacillus thuringiensis subesp. kurstaki in vivo}

Um volume de $25 \mathrm{~mL}$ de cada extrato vegetal (jamboláo, mamona, uva-do-japão e urucum) na concentração $10 \%$ foi colocado separadamente em frascos Erlenmeyer. Em seguida, foi adicionado em cada frasco $0,03 \mathrm{~g}$ do produto comercial, equivalente à metade da concentração recomendada para o controle de A. gemmatalis, conforme determinado no item anterior. Como testemunhas, foram preparados frascos com água destilada esterilizada (testemunha absoluta); água destilada esterilizada + Btk e somente extratos vegetais. Em seguida, os frascos foram incubados em agitador horizontal à temperatura de $30 \pm 2^{\circ} \mathrm{C}, 150 \mathrm{rpm}$ por $2 \mathrm{~h}$. Os procedimentos para aplicaçáo dos tratamentos, acondicionamento e avaliação de mortalidade foram os mesmos descritos no item anterior. As lagartas sobreviventes foram avaliadas até o empupamento, registrando-se o percentual de formação de pupas e o peso médio delas. Os dados foram submetidos à análise de variância (teste $\mathrm{F}$ ) e as médias comparadas com as respectivas testemunhas pelo teste de Tukey a 5\% de probabilidade, com auxílio do programa estatístico Sisvar ${ }^{\circledR}$.

\section{RESULTADOS E DISCUSSÃO}

Nenhum dos extratos vegetais, isoladamente, apresentou efeito inseticida sobre $A$. gemmatalis, uma vez que a mortalidade acumulada não diferiu significativamente da testemunha (água destilada esterilizada). Da mesma forma, verificou-se que nenhum extrato vegetal apresentou efeito negativo sobre cristais de Btk, pois na mistura de ambos não houve inibiçẫo do modo de ação do patógeno. Contrariamente, os extratos de uva-do-japão, urucum e mamona associados com Btk causaram mortalidade acumulada de $100 \%$ para $A$. gemmatalis, diferindo significativamente da testemunha com Btk $(80,92 \%)$, indicando sinergismo dos modos de ação. A mortalidade acumulada $(86,12 \%)$ causada pela associaçáo do extrato de jambolão e Btk não diferiu significativamente da testemunha Btk, isoladamente, evidenciando não haver ação sinérgica dos modos de ação sobre $A$. gemmatalis (Tabela 1).

Com referência aos efeitos subletais, verificaram-se que os extratos puros de uva-do-japão, jambolão, urucum e mamona reduziram o percentual de empupamento de A. gemmatalis, com respectivas médias de 54,73; 46,09; 47,19 e $65,73 \%$, diferindo significativamente da testemunha (água destilada esterilizada) (95,74\%). O extrato de jamboláo associado com Btk reduziu significativamente o percentual de empupamento (12,50\%), comparando-se ao extrato isoladamente $(46,09 \%)$ e à testemunha (água destilada esterilizada) (95,74\%). Com relação ao peso das pupas, nenhum tratamento apresentou efeito negativo sobre esse parâmetro, uma vez que não houve diferença significativa entre as médias dos tratamentos (Tabela 1).

$\mathrm{Na}$ avaliação entre os tempos, o percentual de mortalidade de $A$. gemmatalis causada pelos extratos puros não diferiu entre 24, 48 e 72h. Já na associação dos extratos e Btk, a maior mortalidade de $A$. gemmatalis ocorreu no tempo de $48 \mathrm{~h}$, 
Tabela 1. Porcentagem média ( \pm erro padrão) da mortalidade nos tempos de $24,48,72$ horas e acumulada, porcentagem de empupamento e peso médio de pupas de Anticarsia gemmatalis tratadas com extratos vegetais aquosos (10\%) e Bacillus thuringiensis subesp. kurstaki após incubação $\left(30 \pm 2^{\circ} \mathrm{C}, 150\right.$ rotações por minuto, 2 horas) com e extratos vegetais aquosos (10\%). Temperatura $26 \pm 2^{\circ} \mathrm{C}, 12$ horas de fotofase e umidade relativa de $70 \pm 10 \%$.

\begin{tabular}{|c|c|c|c|c|c|c|}
\hline & \multicolumn{3}{|c|}{ Tempo (h) } & \multirow{2}{*}{$\begin{array}{c}\text { Mortalidade } \\
\text { acumulada (\%) }\end{array}$} & \multirow{2}{*}{$\begin{array}{c}\text { Empupamento } \\
\text { (\%) }\end{array}$} & \multirow{2}{*}{$\begin{array}{l}\text { Peso médio de } \\
\text { pupas }(\mathrm{g})\end{array}$} \\
\hline & 24 & 48 & 72 & & & \\
\hline Test $^{1}$ água & $4,00 \pm 1,63 \mathrm{Aab}$ & $8,00 \pm 1,63 \mathrm{Ab}$ & $10,00 \pm 1,15 \mathrm{Aa}$ & $22,00 \pm 1,15 c$ & $95,74 \pm 1,50 a$ & $3 \pm 0,00 \mathrm{a}$ \\
\hline Test água + Btk ${ }^{2}$ & $17,04 \pm 8,06 \mathrm{Bab}$ & $73,79 \pm 7,33 \mathrm{Aa}$ & $7,13 \pm 4,12 \mathrm{Ba}$ & $80,92 \pm 7,43 b$ & * & * \\
\hline Uva Jap ${ }^{3}$ & $4,88 \pm 2,81 \mathrm{Aab}$ & $3,85 \pm 3,75 \mathrm{Ab}$ & $4,99 \pm 2,56 \mathrm{Aa}$ & $13.72 \pm 5,74 \mathrm{c}$ & $54,73 \pm 7,43 b$ & $0,13 \pm 0$ \\
\hline Uva Jap + Btk & $9,85 \pm 2,17 \mathrm{Bab}$ & $90,15 \pm 2,00 \mathrm{Aa}$ & $0,00 \pm 0,00 \mathrm{Ba}$ & $100,00 \pm 0,00 a$ & * & * \\
\hline $\mathrm{Jam}^{4}$ & $1,00 \pm 1,00 \mathrm{Ab}$ & $8,96 \pm 3,90 \mathrm{Ab}$ & $3,00 \pm 1,90 \mathrm{Aa}$ & $12,96 \pm 6,73 c$ & $46,09 \pm 5,10 b$ & $3 \pm 0,00 a$ \\
\hline Jam + Btk & $13,00 \pm 1,92 \mathrm{Bab}$ & $61,00 \pm 6,80 \mathrm{Aa}$ & $12,12 \pm 5,16 \mathrm{Ba}$ & $86,12 \pm 8,72 a b$ & $12,50 \pm 12,50 \mathrm{c}$ & $0,15 \pm 0,00 \mathrm{a}$ \\
\hline Uru $^{5}$ & $2,92 \pm 1,70 \mathrm{Aab}$ & $6,85 \pm 1,85 \mathrm{Ab}$ & $2,88 \pm 2,75 \mathrm{Aa}$ & $12,65 \pm 8,72 c$ & $47,19 \pm 8,07 b$ & $0,15 \pm 0,00 a$ \\
\hline Uru + Btk & $10,00 \pm 3,46 \mathrm{Bab}$ & $89,00 \pm 2,52 \mathrm{Aa}$ & $1,00 \pm 1,00 \mathrm{Ba}$ & $100,00 \pm 6.25 a$ & * & * \\
\hline $\mathrm{Mna}^{6}$ & $5,00 \pm 3,00 \mathrm{Aab}$ & $10,00 \pm 3,46 \mathrm{Ab}$ & $1,00 \pm 1,00 \mathrm{Aa}$ & $16,00 \pm 1,63 c$ & $65,73 \pm 6,23 b$ & $0,14 \pm 0,00 a$ \\
\hline Mna + Btk & $19,63 \pm 6,38 \mathrm{Ba}$ & $76,32 \pm 4,42 \mathrm{Aa}$ & $4,05 \pm 2,84 \mathrm{Ca}$ & $100,00 \pm 0,00 a$ & * & * \\
\hline \multicolumn{2}{|c|}{ Coeficiente de variação } & 45,16 & & 15,13 & 29,01 & 12,41 \\
\hline
\end{tabular}

Médias ( \pm erro padrão) seguidas pela mesma letra minúscula na coluna e maiúscula na linha não diferem significativamente entre si pelo teste

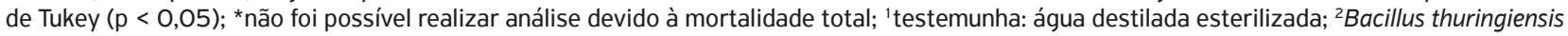
subesp. kurstaki; ${ }^{3}$ uva-do-japão; ${ }^{4}$ jambolão; ${ }^{5}$ urucum; ${ }^{6}$ mamona.

diferindo significativamente dos demais tempos. Resultado semelhante foi verificado para Btk isoladamente, evidenciando que os cristais da bactéria e, consequentemente, o modo de ação não foram afetados negativamente (Tabela 1 ).

A mortalidade acumulada de $A$. gemmatalis (100\%) causada pelo extrato de mamona associado com Btk foi expressivamente maior do que a do extrato isoladamente (16\%), evidenciando que o mesmo náo afetou a atividade tóxica de Btk.

Em estudo semelhante, Santiago et al. (2008) observaram que o extrato aquoso de frutos verdes de mamona a $10 \%$ provocou um alongamento do período larval, inibiçáo do crescimento, deterrência alimentar, além de aumentar a duraçấo do período de pupa e reduzir o peso médio das pupas de Spodoptera frugiperda (Lepidoptera: Noctuidae).

A associação positiva entre mamona e Btk também foi verificada por Rizwan-UL-HaQ et al. (2009) contra Spodoptera exigua (Lepidoptera: Noctuidae). De acordo com os autores, a combinação da ricinina, obtida a partir do extrato de sementes e folhas de mamona, com Btk resultou no significativo aumento da eficiência dessa substância sobre a mortalidade das lagartas, chegando a $87,82 \%$ em comparaçáo ao tratamento individual $(82,11 \%)$. Também verificaram que a ricinina retardou o crescimento larval quando adicionada na dieta artificial, de modo proporcional ao aumento da concentração utilizada, bem como a diminuição do peso larval e inibiçáo do desenvolvimento.

A capacidade inseticida da mamona se deve à ricina, um alcaloide extremamente tóxico (Lima et al., 2011). Como esse alcaloide é encontrado no endosperma da semente, possivelmente a baixa mortalidade observada neste estudo, sem a bactéria (16\%), se deve à utilização de folhas da planta na obtenção do extrato.
O extrato de jamboláo, isoladamente, causou mortalidade de $12,96 \%$ das lagartas, enquanto que na associaçấo com Btk a mortalidade foi significativamente maior $(86,12 \%)$, indicando que o extrato também não interferiu na atividade tóxica da bactéria.

Resultados semelhantes aos obtidos neste estudo foram observados para o extrato aquoso de cascas de jamboláo, em avaliação da atividade antibacteriana contra cepas de isolados padrão e resistente de Vibrio spp. (bactérias Gram negativas patogênicas ao homem), o qual não apresentou atividade vibriocida (SHARMa et al., 2009).

As folhas de jambolão, matéria prima utilizada no presente trabalho, possuem como principais constituintes taninos e saponinas. De acordo com TsuchiYa et al. (1996), essas substâncias podem agir se ligando a proteínas extracelulares e paredes celulares de bactérias, inativando-as. A bioatividade sobre insetos está atribuída à capacidade dos taninos em se ligar às proteínas, dificultando a digestão (MAIRESSE, 2005). Saponinas são compostos secundários da classe dos triterpenos e desempenham um importante papel de defesa nas plantas contra insetos e micro-organismos (Peres, 2005). Segundo o autor, em situaçáo de ataque de insetos, as plantas podem desenvolver saponinas como análogos de hormônios esteroides de insetos, interferindo no seu desenvolvimento, tornando-os estéreis.

$\mathrm{O}$ extrato de jamboláo não apresentou efeito inseticida $\mathrm{e}$ bactericida no presente estudo. Já o extrato de urucum, isoladamente, causou $12,65 \%$ de mortalidade de $A$. gemmatalis, enquanto que na associaçáo do extrato com Btk a mortalidade foi de $100 \%$.

Assim como o jamboláo, o extrato de urucum apresenta em sua composição saponinas e taninos, além de flavonoides, 
alcaloides e esteroides (CoelHo et al., 2003). Náo há estudos com extratos aquosos de jamboláo sobre bactérias entomopatogênicas e insetos. Porém, sabe-se que os alcaloides são substâncias de defesa da planta, que muitas vezes inibe a digestão de herbívoros, sendo que algumas dessas substâncias só são sintetizadas pela planta ela se for atacada por um inseto ou patógeno (MAIRESSE, 2005).

Com relaçấo à uva-do-japão, o efeito da associação do extrato e Btk para o controle de A. gemmatalis também foi positiva, pois a mortalidade acumulada das lagartas foi de $100 \%$, enquanto que para o extrato isoladamente, foi de $13,72 \%$. Essa planta tem sido testada principalmente quanto ao seu poder alelopático, atribuindo-se essa eficiência principalmente à presença de saponinas, flavonoides e alcaloides encontrados em folhas frescas, secas e pseudofrutos da espécie (WANDSCHEER et al., 2011). Não foram encontrados relatos sobre o efeito dessa espécie sobre bactérias.

No presente trabalho, a redução significativa no percentual de empupamento de $95,74 \%$ na testemunha para 54,73 ; 46,$09 ; 47,19$ e $65,73 \%$, respectivamente, para os extratos de uva-do-japão, jamboláo, urucum e mamona pode ser explicada pela grande variedade de compostos secundários encontrados nos extratos testados. Nesse caso, observaram-se que os extratos apresentaram efeito secundário sobre a formação das pupas, fortalecendo a tese de que aleloquímicos extraídos de plantas, por possuírem características insetistáticas, podem não apresentar ação aguda contra insetos-praga, mas poderão, no final de uma geração, reduzir a população da praga para níveis iguais ou inferiores àqueles encontrados com a utilização de produtos com acentuada ação inseticida (Torres et al., 2001).

Segundo KnaAK et al. (2010), os ingredientes ativos tóxicos encontrados nos extratos vegetais podem atuar no intestino médio dos insetos, fato observado em análise histopatológica de lagartas de $S$. frugiperda, após ingestão de extratos de guiné Petiveria alliacea (L.) (Phytolaccaceae), gengibre, Zingiber offcinale (Roscoe) (Zingiberaceae), capim-limão, Cymbopogon citratus (Stapf.) (Poaceae), malva, Malva silvestris (L.) (Malvaceae), carqueja, Baccharis genistelloides (Less)
(Asteraceae), e arruda, Ruta graveolens (L.) (Rutaceae), e a associação desses extratos com a bactéria entomopatogênica Bacillus thuringiensis subesp. aizawai. De acordo com os autores, a toxicidade dos extratos causou danos como: vacuolizaçáo do citoplasma, rompimento das microvilosidades, destruiçấo da membrana peritrófica e alteraçôes nas células do intestino médio de $S$. frugiperda. Além disso, a associação dos extratos e B. thuringiensis subesp. aizawai acelerou o processo de destruiçáo das células intestinais, reduzindo o tempo letal da espécie alvo $S$. frugiperda, quando foram utilizados em conjunto.

O controle de pragas pode ser potencializado com a utilização de extratos de plantas em associação com entomopatógenos. Acredita-se que se o extrato ocasionar um efeito estressor sobre a praga pode levá-la a adquirir ou ativar doenças infecciosas, tornando-a mais suscetível às toxinas de Btk, proporcionando uma ação mais rápida do entomopatógeno ou um maior índice de mortalidade (SAIto; LuChINI, 1998). Isso foi constatado por SABBour (2003) quando utilizou extrato do cipreste Taxodium distichum (L. Rich) associado com B. thuringiensis, pois tal associação causou um aumento na patogenicidade da bactéria para pragas de produtos armazenados.

No presente estudo, além de nenhum extrato ter inibido a atividade tóxica do cristal proteico de Btk, verificou-se que os extratos apresentaram efeito aditivo quando utilizados em associação com a bactéria. Novos testes podem ser realizados utilizando outras formas de extração na preparação dos extratos em laboratório, buscando maiores concentraçóes de metabólitos secundários. Além disso, poderão ser testadas outras concentraçóes além das utilizadas no presente estudo com o objetivo de potencializar a ação desses dois agentes de controle.

Os extratos vegetais aquosos de jambolão, mamona, uva-do-japão e urucum nấo causaram mortalidade significativa de $A$. gemmatalis, porém, apresentaram efeito sobre a formaçáo de pupas. Nenhum dos extratos apresentou efeito negativo sobre os cristais de B. thuringiensis subesp. kurstaki, porém, a mistura dos extratos de mamona, uva-do-japão e colorau com Btk ocasionou um aumento na mortalidade de $A$. gemmatalis, indicando que essas estratégias de controle podem ser utilizadas simultaneamente.

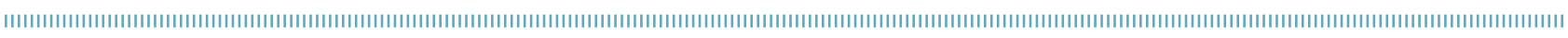

\section{REFERÊNCIAS}

BERLITZ, D.L.; FIUZA, L.M. Bacillus thuringiensis e Melia azedarach: aplicações e interações no controle de insetospraga. Biotecnologia Ciência \& Desenvolvimento, n.35, p.66-72, 2005.

BRAVO, A.; GILL, S.S.; SOBERÓN, M. Mode of action of Bacillus thuringiensis $\mathrm{Cry}$ and $\mathrm{Cit}$ toxins and their potential for insect control. Toxicon, v.49, n.4, p.423-435, 2007.

COELHO, A.M.S.; SILVA, G.A.; VIEIRA, O.M.C.; CHAVASCO, J.K. Atividade antimicrobiana de Bixa orellana L. (Urucum). Revista Lecta, v.21, n. 1-2, p.47-54, 2003.
DINIZ, L.P.; MAFFIA, L.A.; DHINGRA, O.D.; CASALI, V.W.D.; MIZUBUTI, R.H.S.; MIZUBUTI, E.S.G. Avaliação de produtos alternativos para controle da requeima do tomateiro. Fitopatologia Brasileira, v.31, n.2, p.171-179, 2006.

FIUZA, L.M. Mecanismo de ação de Bacillus thuringiensis. Biotecnologia Ciência \& Desenvolvimento, n.38, 2009.

FRANÇA, S.M.; OLIVEIRA, C.M.; PICANÇO, M.C.; LÔBO, A.P. Efeitos ovicida e repelentes de inseticidas botânicos e sintéticos em Neoleucinoides elegantalis (Guenée) (Lepidoptera: Crambidae). Boletín de Sanidad Vegetal Plagas, n.35, p.649-655, 2009. 
GLIESSMAN, S.R. Agroecologia: processos ecológicos em agricultura sustentável. $3^{a}$ ed. Porto Alegre: Editora da UFRGS, 2005.

HABIB, M.E.M; ANDRADE, C.F.S. Bactérias entomopatogênicas. In: ALVES S.B.(Ed.), Controle microbiano de insetos. $2^{2}$ ed. Piracicaba: FEALQ, 1998. p.383-427.

HOFFMANN-CAMPO, C.B.; OLIVEIRA, E.B.; MOSCARDI, F. Criação massal da lagarta da soja (Anticarsia gemmatalis). Documentos 10. Londrina: EMBRAPA-CNPSo, 1985.

KNAAK, N.; TAGLIARI, M.S.; FIUZA, L.M. Histopatologia da interação de Bacillus thuringiensis e extratos vegetais no intestino médio de Spodoptera frugiperda (Lepidoptera: Noctuidae). Arquivos do Instituto Biológico, v.77, n. 1, p.83-89, 2010.

LIMA, B.M.F.V.; MOREIRA, J.O.T.; PINTO, H.C.S. Avaliação de extratos vegetais no controle de mosca branca em tomate. Revista Caatinga, v.24, n.4, p.36-42, 2011

LOGUERCIO, A.P.; BATTISTIN, A.; VARGAS, A.C.; HENZEL, A.; WITT, N.M. Atividade antibacteriana de extrato hidro-alcoólico de folhas de jambolão (Syzygium cumini (L.) Skells). Ciência Rural, v.35, n.2, p.371-376, 2005.

MAIRESSE, L.A.S. Avaliação da bioatividade de extratos de espécies vegetais, enquanto excipientes de aleloquímicos. 2005. 330f. Tese (Doutorado) - Universidade Federal de Santa Maria, Santa Maria, 2005.

MATIAS, E.F.F; SANTOS, K.K.A.; ALMEIDA, T.S.; COSTA, J.G.M.; COUTINHO, H.D.M. Atividade antibacteriana in vitro de Croton campestris A., Ocimum gratissimum L. e Cordia verbenacea DC. Revista Brasileira de Biociências, v.8, n.3, p.294-298, 2010.

MEDEIROS, C.A.M.; BOIÇA JUNIOR, A.L.; TORRES, A.L. Efeito de extratos aquosos de plantas na oviposição da traça-dascrucíferas, em couve. Bragantia, v.64, n.2, p.227-232, 2005b.

MEDEIROS, P.T; FERREIRA, M.N.; MARTINS, E.S.; GOMES, A.C.M.M.; FALCÃO, R.; DIAS, J.M.C.S.; MONNERAT, R.G. Seleção e caracterização de estirpes de Bacillus thuringiensis efetivas no controle da traça-das-crucíferas Plutella xylostella. Pesquisa Agropecuária Brasileira, Brasília, v.40, n. 1 1, p. 1 145-1 148, 2005a.

MICHELIN, D.C.; MORESCHI, P.E.; LIMA, A.C.; NASCIMENTO, G.G.F.; PAGANELLI, M.O.; CHAUD, M.V. Avaliação da atividade antimicrobiana de extratos vegetais. Revista Brasileira de Farmacognosia, v.14, n.4, p.316-320, 2005.

PENTEADO, S.R. Defensivos alternativos e naturais. $3^{\text {a }}$ ed. Campinas: Ed. Livros Via Orgânica, 2007.

PERES, L.E.P. Metabolismo secundário: terpenos. In: CASTRO, P.R.C.; KLUGE, R.A.; PERES, L.E.P. Manual de fisiologia vegetal: teoria e prática. São Paulo: Livroceres, 2005. 650p.

PRAÇA, L.B.; BATISTA, A.C.; MARTINS, E.S.; SIQUEIRA, C.B.; DIAS, D.G.S.; GOMES, A.C.M.M.; FALCÃO, R.; MONNERAT, R.G. Estirpes de Bacillus thuringiensis efetivas contra insetos das ordens Lepidoptera, Coleoptera e Diptera. Pesquisa Agropecuária Brasileira, v.39, n.1, p.11-16, 2004.
PRATES, H.T.; VIANA, P.A.; WAQUIL, J.M. Atividade de extrato aquoso de folhas de nim (Azadirachta indica) sobre Spodoptera frugiperda. Pesquisa Agropecuária Brasileira, v.38, n.3, p.437-439, 2003.

RIZWAN-UL-HAQ, M.; HU, Q.B.; HU, M.Y.; LIN, Q.S.; ZHANG, W.L. Biological impact of harmaline, ricinine and their combined effects with Bacillus thuringiensis on Spodoptera exigua (Lepidoptera: Noctuidae). Journal Pest Science, v.82, p.327-334, 2009.

SABBOUR, M. Combined effects of some microbial control agents mixed with botanical extracts on some stored product insects. Pakistan Journal of Biological Sciences, v.6, n. 1, p.51-56, 2003.

SAITO, M.L.; LUCCHINI, F. Substâncias obtidas de plantas e a procura por praguicidas eficientes e seguros ao meio ambiente. Jaguariúna: EMBRAPA-CNPMA, 1998.

SAITO, M.L.; POTT, A.; FERRAZ, J.M.G.; NASCIMENTO, R.S. Avaliação de plantas com atividade deterrente alimentar em Spodoptera frugiperda (J.E.SMITH) e Anticarsia gemmatalis HUBNER. Pesticidas: Revista de Ecotoxicologia e Meio Ambiente, v.14, p.1-10, 2004.

SANTIAGO, G.P.; PÁDUA, L.E.M.; SILVA, P.R.R.; CARVALHO, E.M.S.; MAIA, C.B. Efeitos de extratos de plantas na biologia de Spodoptera frugiperda (J.E. Smith, 1797) (Lepidoptera: Noctuidae) mantida em dieta artificial. Ciência e Agrotecnologia, v.32, n.3, p.792-796, 2008.

SANTOS, K.B.; NEVES, P.; MENEGUIN, A.M.; SANTOS, R.B.; SANTOS, W.J.; VILLAS BOAS, G.; DUMAS, V.; MARTINS, E.; PRAÇA, L.B; QUEIROZ, P.; BERRY, C.; MONNERAT, R. Selection and characterization of the Bacillus thuringiensis strains toxic to Spodoptera eridania (Cramer), Spodoptera cosmioides (Walker) and Spodoptera frugiperda (Smith) (Lepidoptera: Noctuidae). Biological Control, v.50, n.1, p.157-163, 2009.

SCHLÜTER, M.A. Avaliação de extratos vegetais no controle de Anticarsia gemmatalis HÜBNER, 1818 (Lepdoptera: Noctuidae) sob diferentes pressões populacionais a campo. 2006. $77 \mathrm{f}$. Dissertação (Mestrado) - Programa de Pós-Graduação em Agronomia, Universidade Federal de Santa Catarina, Santa Maria, 2006.

SHARMA, A.; PATEL, V.K.; RAMTEKE, P. Identification of vibriocidal compounds from medicinal plants using chromatographic fingerprinting. World Journal of Microbiology and Biotechnology, v.25, n. 1, p.19-25, 2009

TORRES, A.L.; BARROS, R.; OLIVEIRA, J.V. Efeito de extratos aquosos de plantas no desenvolvimento de Plutella xylostella (L.) (Lepidoptera: Plutellidae). Neotropical Entomology, v.30, n. 1, p.151-156, 2001.

TSUCHIYA, H.; SATO, M.; MIYAZAKI, T.; FUJIWARA, S.; TANIGAKI, S.; OHYAMA, M.; TANAKA, T.; IINUMA, M. Comparative study on the antibacterial activity of phytochemical flavanones against methicillin resistant Staphylococcus aureus. Journal of Ethnopharmacology, v.50, n. 1, p.27-34, 1996.

WANDSCHEER, A.C.D.; BORELLA, J.; BONATTI, L.C.; PASTORINI, L.H. Atividade alelopática de folhas e pseudofrutos de Hovenia dulcis Thunb. (Rhamnaceae) sobre a germinação de Lactuca sativa L. (Asteraceae). Acta Botanica Brasilica, v.25, n. 1, p.25-30, 2011. 